\title{
Niñez y régimen disciplinario: una mirada sociocultural a la educación de antaño
}

DOI: https://doi.org/10.32870/dse.v0i10.283

\section{Oscar Reyes Ruvalcaba* Celia Luévanos Aguirre** Eurídice Minerva Ochoa Villanueva***}

Resumen: El presente artículo es producto parcial de un proceso de investigación que desarrolla el cuerpo académico 74 de la Universidad Pedagógica Nacional (México). Tiene como propósito dar cuenta de la manera como era disciplinada la niñez a principios del siglo XX. Se apoya en los desarrollos conceptuales sobre régimen disciplinario de Michel Foucault (1970 y 1983). Muestra la forma en que el evolucionismo social, propuesto por Herbert Spencer a finales del siglo XIX, penetró en los educadores mexicanos y otorgó una visión racista, clasista y machista de la naturaleza infantil. Esta visión se tradujo en políticas educativas con una normatividad rígida y de índole marcial, así como en prácticas pedagógicas donde imperaba el autoritarismo docente y la exigencia de la obediencia irrestricta del alumnado. Sin embargo, considera que las y los menores resistían este régimen disciplinario con pequeñas trampas, sagacidad y otras artimañas. Palabras claves: historia de la niñez; régimen disciplinario; políticas educativas; naturaleza infantil; prácticas pedagógicas.

\begin{abstract}
This article is a partial product of a research process that develops the academic body 74 of the Universidad Pedagógica Nacional (México). It aims to give an account of the way as it was disciplined the children at the beginning of the $20^{\text {th }}$ century. It relies on conceptual developments on disciplinary regime of Michel Foucault (1970 and 1983). Sample the way social evolutionism, proposed by Herbert Spencer at the end of the 2oth century, entered the mexican educators and granted a racist, classist and sexist view of child nature. This vision was translated with a rigid regulations and martial nature educational policies, as well as pedagogical practices where ruled teaching authoritarianism and demands for unrestricted obedience of students. However, it is considered that the child resisted this disciplinary regime with small traps, sagacity and other tricks. Keywords: history of childhood; disciplinary regime; educational policies; child nature; pedagogical practices.
\end{abstract}

\section{Introducción}

Este artículo tiene como propósito dar conocer la forma como era disciplinada la niñez a finales del siglo XIX y principios del siglo XX en México y particularmente en Jalisco. En términos generales, procuramos responder a la siguiente interrogante: ¿Qué relaciones existían entre los discursos en torno a la educación y las maneras prácticas en que cotidianamente eran formados los niños y las niñas?

* Universidad Pedagógica Nacional -Unidad Colima. Docente del Doctorado en Educación de la Universidad Pedagógica Nacional -Unidad Guadalajara. León Polanco No. 262; C.P. 28979, Villa de Álvarez, Colima. Tel.: (312) 320 3256. Correo electrónico: oscar_reyes_ruvalcaba@yahoo.com.mx

** Universidad Pedagógica Nacional -Unidad Guadalajara. Coordinadora del Doctorado en Educación de la Universidad Pedagógica Nacional. Av. Plan de San Luis No.1696. Col. Chapultepec Country; C.P. 44260. Guadalajara, Jalisco. Tel.: (33) 3823 6572. Correo electrónico: celia.lue.a@gmail.com

*** Universidad Pedagógica Nacional -Unidad Guadalajara. Doctorado en Educación de la Universidad Pedagógica Nacional. Av. Plan de San Luis No.1696. Col. Chapultepec Country; C.P. 44260. Guadalajara, Jalisco. Tel.: (33) 3823 6572. Correo electrónico: minervaochoa@gmail.com 
Para responder a este cuestionamiento sostenemos el siguiente argumento: A principios del siglo XX en México predominó un discurso educativo de corte positivista, asociado al evolucionismo social de Herbert Spencer. Las leyes y reglamentos escolares durante el porfiriato se fundamentaron en este paradigma. Sin embargo, la práctica en la educación elemental estaba centrada en la disciplina y el castigo, producto de una historia y un medio social generado por la violencia publica y doméstica.

Para desarrollar este argumento dividimos el estudio en diversos apartados. Primero realizamos una aproximación a los conceptos de disciplina con base en Michel Foucault, pues consideramos que su perspectiva teórica nos permite comprender las funciones sociales de la violencia institucionalizada y su impacto en las prácticas educativas. Posteriormente, a manera de antecedentes, realizamos una síntesis de la forma disciplinaria de educar a los niños durante el siglo XIX. En el tercer apartado damos cuenta de la concepción de naturaleza infantil en Herbert Spencer y su influencia en los educadores e intelectuales mexicanos, tomando como ejemplo la flexible interpretación que hacÍa el doctor y maestro mexicano Máximo Silva. En la cuarta parte mostramos cómo el discurso positivista concretaba en la normatividad educativa de entonces, tomando como muestra el Reglamento de Instrucción Pública del Estado de Jalisco instaurado en 1904. Finalizamos el artículo exponiendo las formas concretas cómo dicha normatividad se expresaba en las prácticas educativas cotidianas y era percibida por los menores de antaño. Sin embargo, aclaramos que si bien la educación era obligatoria para todos los niños, la población que mayoritariamente asistía a las escuelas públicas era principalmente de clase media y media baja.

Respecto a la selección de fuentes, consideramos que son las más representativas para dar cuenta de nuestro objeto de estudio: la disciplina escolar a inicios del siglo XX. El uso de memorias y fuentes literarias es un recurso utilizado por los historiadores culturales para exponer el punto de vista de los actores, pues la nueva historia no sólo está interesada en las estructuras, sino también en los procesos y sujetos cotidianos de la historia.

\section{De normas y disciplina}

A principios del siglo XX el Estado concebía a la escuela como el principal vehículo de "normalización" de la infancia, es decir, como un medio que permitía a los menores interiorizar las normas sociales y modelar su conducta. El confinamiento de niñas y niños en áreas especializadas de estudio; el sometimiento de los menores a ritmos secuenciados en las escuelas; y la disposición jerárquica según el conocimiento de los pequeños, tenían como propósito lograr la docilidad de los infantes para una sociedad donde el "orden y progreso" se convirtió en el principio rector de las políticas públicas.

Este escrupuloso control infantil obedecía a lo que Foucault (1983) llamaba un "ordenamiento reglamentario", a través del cual se persuadía a los menores a ajustarse a la normatividad institucio- 
Niñez y régimen disciplinario: una mirada sociocultural a la educación de antaño

nal. De no someterse a la regla, los menores se harían acreedores de una "sanción normalizadora", pues en la escuela reinaba una verdadera micropenalidad del tiempo, de la actividad y del cuerpo.

Todos estos procedimientos de control se pueden resumir con un término: disciplina. De acuerdo con Foucault, la disciplina es "un orden artificial, dispuesto de manera explícita por una ley, un programa, un reglamento. Pero es también un orden definido por unos procesos naturales y observables: la duración de un aprendizaje, el tiempo de un ejercicio, el nivel de aptitud [de los alumnos]" (1983: 184). Es decir, la disciplina no sólo está prescrita por la normatividad escolar, sino se manifiesta en las prácticas educativas. Identificar la disciplina existente en un establecimiento escolar requiere reconocer la forma en que prácticamente operaba la normatividad institucional en ese entorno educativo. En el caso de México, ¿de dónde provenía esa mirada disciplinar de la infancia y de la educación?

\section{Infancia y educación en la historia social del siglo XIX}

A decir de Jacques Lafaye, en los inicios del siglo XIX existían en las principales ciudades novohispanas muchos menores que pasaban la mayor parte del tiempo en las empolvadas calles urbanas. En su mayoría esos infantes eran considerados "hijos de nadie", en el sentido de que no pertenecían a una comunidad socialmente reconocida - como la española o la indígena-. Sin embargo, esos menores desarraigados pasaron a ser hijos de la Virgen de Guadalupe, y con su sangre mestiza contribuyeron a la construcción de una nueva identidad nacional. No en vano el Miguel Hidalgo condujo a los insurrectos con la imagen de una Guadalupana como estandarte (Lafaye, 2002).

Es de suponer que algunos de estos bribonzuelos también participaron durante las guerras de Independencia nacional. Muchos de estos pequeños maduraron y se hicieron hombres al fragor de la batalla, en uno u otro frente. En una revisión sobre el periodo de emancipación nacional, Guadalupe Jiménez señala que los menores realizaban los siguientes papeles:

a) como rehén para lograr la liberación de alguien o para conseguir que su padre o su madre dejen las armas;

b) como soldado u oficial en las partidas insurgentes o en la tropa realista; c) como mensajero o correo, a veces espía, utilizado por ambos bandos;

d) como auxiliar o voluntario en los campamentos y partidos rebeldes o realistas;

e) como víctima inocente de la devastación del hogar, de su pueblo y de su patria (1997: 146147).

Las luchas de independencia sólo pudieron producir mayor orfandad, lo cual provocó que aumentara el número de pequeños que andaban sin oficio ni beneficio por las calles, en donde aprendían a ser embusteros, dicharacheros, advenedizos, ocurrentes o, en otras palabras, pícaros de gran ralea. 
Artemio Valle-Arizpe recreó la vida de uno de éstos pequeños llamado Félix Vargas. Cuando este menor fue expulsado de la morada en la que le brindaban cobijo, trabajo y cristiana educación “.... el mocito volvió a dar a su vida un rumbo picaresco. Fue a parar a los lodazales de la miseria entre una turba de galopines de su misma edad, estofa, y como él de estragadas costumbres que vivían del hampa y medraban con el fraude y los embutes" (1990: 45). Según este autor, turbas de pequeños mugrosos y desarrapados deambulaban por la ciudad de México alterando el orden, causando destrozos, provocando escándalo y cometiendo cualquier sarta de fechorías con el objetivo de conseguir recursos para saciar su hambre voraz.

Para controlar esta chiquillada callejera fue la Iglesia quien principalmente se preocupó por inculcarles cristianos valores e introdujo en espacios anexos a las parroquias improvisados salones en los que también se les enseñaba los rudimentos de las letras y los números. Pero los menores debían desarrollar algunas mañas para sortear la estricta disciplina y el mal trato que recibían en manos de los maestros, pues éstos consideraban que "la letra con sangre entra", lo cual era causante de los errores estudiantiles, tal como lo señalara el Periquillo Sarniento:

Cuando iba o me llevaban a la escuela, ya entraba ocupado de un temor imperdonable; con esta mi mano trémula y mi lengua balbuceante ni podía formar un renglón bueno ni articular una palabra en su lugar, todo lo erraba, no por falta de aplicación, sino por sobra de miedo: a mis yerros seguían los azotes, a los azotes más miedos, más torpeza en mi mano y en mi lengua, lo que me granjeaba más castigo (Fernández, 2001: 26).

Los años posteriores a nuestra Independencia estuvieron marcados por la miseria, el caos y las guerras intestinas. Es de considerar que de nuevo eran los pequeños léperos quienes mejor podían sobrevivir en ese entorno de escasez y hostilidad permanente. Es posible rastrear la forma como vivieron estos menores a través de autobiografías como la de Guillermo Prieto. Este intelectual mexicano señalaba que si el pequeño no procedía de una familia acomodada, o bien, perdía la protección de sus padres, "pasaría las de Caín", como efectivamente a él mismo le ocurrió cuando quedó huérfano de padre y fue abandonado por su madre: "Unas veces vagando perdido y sin que nadie me conociera en los más apartados barrios; otros, dentro de la pequeña vivienda de mis bienhechores aplicándome en los quehaceres domésticos, y otras, con las alegres chicas de la vecindad, sacando partido de mis cuentos y las recitaciones del coloquio famoso, pasaba mi vida" (1996: 20). Sin embargo, en los "hogares decentes" se tenía una concepción muy diferente de la forma en que se debería comportar un menor. A éste se le exigía:

...que se estuviese quietecito horas enteras, en saber un buen trozo de catecismo de memoria, en rezar el rosario en las horas tremendas, comer con tenedor y cuchillo, dar las gracias a tiempo, besar la mano a los padres y decir que quería ser emperador, santo, sacerdote o mártir del Japón. En cuanto a la niña, le era 
Niñez y régimen disciplinario: una mirada sociocultural a la educación de antaño

permitido... hacer comiditas con sus muñecas, comer poco, rezar mucho y no querer jugar al merolico con sus primos, sino ser monja (Prieto, 1996: 12).

Pero no fueron sólo la escuela y la familia los únicos impulsores de la representación de la niñez decimonónica. El ambiente social y político requería la constitución de sujetos que se comportaran civilizadamente, esto es, se requería de la formación de ciudadanos. Beatriz Alcubierre descubrió que el surgimiento de la literatura infantil en la segunda mitad del siglo XIX obedecía a la necesidad que tenía el Estado de hacer del niño un sujeto letrado, y "en su calidad de lector [era] concebido como un ciudadano del futuro" (2003). No bastaba que los adultos leyeran al pequeño, sino había que hacer de cada menor un ser ilustrado que apoyara la construcción del naciente Estado-Nación.

Para la formación de este nuevo ciudadano había que combatir los vicios de los menores de las clases populares, y principalmente "domesticar" su carácter insumiso. La enseñanza de los principios cristianos, la enseñanza elemental gratuita, el aprendizaje de algún oficio, eran algunos medios utilizados para contrarrestar la vagancia de los chicos.

Luz Elena Galván rescató un periódico destinado a la "infancia desvalida": El Obrero del Porvenir. Por medio de este seminario se trató de inculcar a las menores simpatías por la educación, por la religión, por la sana moral y, sobre todo, amor al trabajo. Pues se consideraba que la pereza era una fuente que producía en el menor fastidio, gusto por la vagancia y generaba toda clase de vicios. La laboriosidad se presentaba como guía y "centinela de la virtud". Había que mantener al niño activamente ocupado si se quería evitar los riesgos de la calle. Por ello el discurso del Obrero del Porvenir...

se centra[ba] en la formación del nuevo ciudadano: trabajador, recto. Se trata[ba] de un discurso enfocado a evitar los peligros de la vagancia entre los niños de la clase baja. De aquí el énfasis en el trabajo y en resaltar la importancia de dedicarse a un oficio. Su idea era la de convertirlos en "miembros útiles a la sociedad", que el siglo XIX reclamaba (Galván, 2003: s/p).

Durante el porfiriato se dio un fuerte impulso a la educación elemental, normando sus funciones, uniformando sus métodos, volviéndola obligatoria y gratuita, incentivando a los profesores y construyendo escuelas. Sin embargo, los menores de las ciudades que no asistían a la escuela, que eran la mayoría, eran percibidos como "vagos", "pícaros irredentos", "leperitos" o "adultos precoces", por lo que su carácter de niños quedaba en segundo término y en veces era aún negado. Así lo constató el historiador Alberto Castillo Troncoso quien al realizar un estudio sobre la manera como era representada la "infancia callejera" en la prensa durante el porfiriato, descubrió que estos niños eran representados "como un grupo especial, con elementos de identidad propios, específicos, que los diferencian no sólo de los demás grupos, sino de cualquier otro grupo social" (1998, 391). Solamente por convivir en la vía pública, los sectores altos y medios consideraban que los menores 
de las clases menesterosas tenían un gusto natural por el juego y los cigarrillos y, por tanto, eran delincuentes potenciales a los que se les debía recluir y civilizar. Se olvidaba que la mayoría de estos chicos abandonaba la escuela para realizar alguna actividad remunerativa que apoyara al sostenimiento familiar.

La presencia de estos menores en la calle ofreciendo sus servicios y vendimias molestaba a los sectores cultos de la sociedad porque contravenía la imagen de orden y progreso que pregonaba el régimen porfirista. Durante este periodo se abrieron asilos, hospicios, hospitales, escuelas de artes y oficios y hasta correccionales para ocultar y "civilizar" a esos chiquillos incómodos. Según Beatriz Alcubierre y Tania Carreño, la creación de las instituciones escolares y de beneficencia “.... fue la solución que el porfiriato dio al enorme conflicto que significaba la proliferación de niños desnutridos, sin hogar, harapientos y con propensión a la delincuencia -inclinación ésta que más preocupaba a las élites porfirianas-" (1996: 71).

Mientras que entre las clases acomodadas “....se partía de la premisa de que el niño era un ser bueno por naturaleza, existía la idea de que su misma inocencia lo hacía débil y por tanto corruptible" (Alcubierre \& Carreño, 1996: 63). Por ello, la educación debía contener una buena dosis de rigidez, mediada con premios y recurrentes consejos morales. Tanto en la escuela como en el hogar, a los menores se les debía inculcar el respeto a los mayores, el apego a las normas y una irrestricta fe en el progreso. En suma, una niñez inocente, sumisa, bondadosa, ilustrada y civilizada, era el ideal que perseguían los sectores que dirigían al conjunto de la sociedad porfirista.

\section{Concepciones de naturaleza y desarrollo infantil durante el porfiriato}

Durante el porfiriato surgieron estudios que se ocuparon del cuerpo del niño, de su inteligencia y de su comportamiento. Es decir, alrededor de la infancia se constituyó un nuevo campo del saber, integrado por prácticas pedagógicas, por reglamentaciones jurídicas, por discursos religiosos y por observaciones médicas que tenían a la niñez por objeto a controlar y transformar.

En el México de principios del siglo XX, este campo del conocimiento e intervención estuvo permeado por el positivismo, principalmente en su vertiente de darwinismo social. Esta visión evolucionista, influyó los diferentes saberes y prácticas, tanto académicas como sociales. Así, por ejemplo, se renovó el "derecho natural", se instituyó la "pedagogía objetiva", emergió la "sociología organicista" y se fortaleció la "medicina higienista". En todos estos campos se tenía una concepción evolucionista de la sociedad y del hombre, según la cual la infancia correspondía a una fase primaria del desarrollo humano.

El inglés Herbert Spencer (1820-1903) fue uno de los escritores que más influyó en los intelectuales mexicanos durante el porfiriato. Desde la perspectiva sociológica de Spencer, las etapas del desarrollo individual se correspondían con las fases de la evolución de la humanidad. Así cada persona recorría, a lo largo de su vida, los mismos periodos seguidos por la especia humana. Esta forma de razonamiento tenía implicaciones en las formas de representarse a la niñez, pues a ésta iba 
Niñez y régimen disciplinario: una mirada sociocultural a la educación de antaño

a corresponder con el periodo más primitivo en el avance del género humano: la barbarie. Por ello argumentaba que durante "...los primeros años de su vida.., las facciones del niño se parecen por algún tiempo a las del salvaje, lo mismo sucede con los instintos. De ahí la tendencia a la crueldad, al robo, a la mentira, tan comunes en los niños; tendencias que aun sin el auxilio de la disciplina, se modifican luego como las facciones (Spencer, 1889: 176-177).

¿Cómo penetró esta visión evolucionista en los educadores mexicanos? ¿Qué consecuencias tuvo en la formación escolar de la niñez? Según lo constatan González Navarro (1994), Larroyo (1947) y Meneses (1983), Spencer influyó en educadores mexicanos tan prominentes como Vicente Alcaraz, Luis E. Ruiz, Manuel Flores y Justo Sierra. Y a través de ellos en la formación de los futuros docentes mexicanos. Para muestra un botón: reseñamos el caso del doctor y maestro Máximo Silva.

El doctor mexicano Máximo Silva (1861-1939) combinó su vida entre el magisterio, la investigación y la actividad pública. A principios del siglo XX fue profesor de la Escuela Normal para Profesoras de la capital (Romero, 1939). A partir de 1906, por invitación de Justo Sierra, fungió como responsable del recién creado Departamento de Higiene Escolar dentro de la Dirección General de Educación Primaria, allí se hizo cargo de la Sección de Higiene y Antropometría Escolares (Silva, 1917).

Orientado por el darwinismo social de Spencer, Silva tenía una visión pesimista sobre la naturaleza infantil. Para él, el niño era un ser débil tanto "en el cuerpo como en el alma; extraviado, aun antes de dar los primeros pasos; con tendencias que generalmente conducen al mal; inexperto para conocer los peligros; débil para la fatiga" (Silva, 1917: 12). Estas tendencias de la infancia eran producto de una herencia degenerativa que los padres y abuelos legaban a los nuevos seres. Argumentaba que en el caso de los niños mexicanos predominaba la herencia degenerativa a causa de la debilidad endémica de nuestra raza, y del erróneo comportamiento étnico de los padres. Pues para el doctor Silva la conducta moral era una herencia que se transmitía de generación en generación:

También pudiera agregarse que es grado de aspereza que los niños sufren hoy en el trato que les dan algunos padres y maestros, es sólo una preparación para sufrir la aspereza mayor que encontrarán cuando entren en el mundo, y que si fuese posible a los padres y maestros proceder con equidad perfecta y con entera simpatía, esto no haría más que aumentar los sufrimientos que más tarde les ha de causar el egoísmo de los hombres (Spencer, 1889: 145).

A esta mirada evolucionista y racista, el dr. Silva la reforzaba con una visión machista y misógina, pues consideraba que sobre la familia, y en particular sobre la mujer, recaía la responsabilidad directa del deterioro infantil, pues consideraba que la madre mexicana era la principal responsable de la “... anemia, el raquitismo, en lo físico, el afeminamiento y la sensibilidad exagerada en lo moral, 
tal es el patrimonio que, a fuerza de amor y de ternura, solemos legar a nuestros hijos" (Silva, 1917, pp. 262-263).

Para este higienista había que dejar que los menores sufrieran un poco para que aprendieran a cuidarse por sí mismos, pues un niño “...educado por mujeres y entre mujeres, se afemina; habituado a las comodidades, al ocio y al bienestar, encuentra el trabajo odioso" (Silva, 1917, p. 263). Par él, los accidentes, caídas, tropiezos, raspones, y magulladuras, eran la mejor institutriz de la vida. Ese era el precio que había que pagar para que los niños, más tarde, merecieran ser llamados hombres.

La sujeción a una férrea disciplina, la obediencia ciega, el esfuerzo y el sacrificio viril, eran algunas de las formas que el doctor proponía para que los menores desarrollaran mayor fuerza y vigor. Por lo que se requería una orientación viril, que los formara en la templanza del cuerpo y del alma. Consideraba que a la niñez sólo se le educaba con disciplina y respeto a la autoridad. Argumentaba:

Hasta la edad de siete u ocho años, es sobre manera ventajoso mantener intacta la autoridad sobre los niños, y dirigirse pura y sencillamente al sentimiento de la obediencia. Esta obediencia ha de ser ciega; y hasta despojada de la idea de obligación. Las nociones del deber vendrán después y reforzarán, todavía más, el sentimiento de la obediencia... (Silva, 1917, p. 262).

Sólo cuando la educación caminara bajo la más estricta disciplina se llegaría a hacer de los escolares hombres racionalmente ilustrados; moralmente justos; patriotas viriles; civilizados y emprendedores, ya que "cuando se dice que un ejército es disciplinado se quiere expresar que se ha habituado a la sumisión, que sabe obedecer, sobreponiéndose al temor, con una obediencia serena, marcial, valerosa" (Silva, 1917, p. 266).

\section{Disciplina en las escuelas elementales}

Esta visión pesimista de la naturaleza de la niñez, orientó al gobierno a implementar una enseñanza centrada en la disciplina y el castigo, pues se tenía la convicción de que sólo era posible normar el carácter rebelde de los menores por medio de la educación. Pues, como reconocía el educador colimense Gregorio Torres Quintero, la escuela constituía “...la madre del ciudadano, la cuna de la patria, el plantel de virtudes cívicas, la fuente de la riqueza, la llave de oro de los derechos del hombre" (Torres Quintero, en Zea, 1962: 143).

En el caso Jalisco tanto el Estado como la Iglesia impulsaron escuelas y colegios para lograr el control sobre la conducta de los menores. Por ejemplo, en 1905 se celebraban semanalmente las Academias Pedagógicas, en las que los profesores tapatíos se enteraban de las últimas novedades educativas implementadas en la Normal y en su Escuela Práctica Anexa. Ese mismo año se creó la Inspección de Higiene y Salud Escolares con el fin de verificar - tanto en los establecimientos 
Niñez y régimen disciplinario: una mirada sociocultural a la educación de antaño

oficiales como en los particulares - que los menores contaran con los requerimientos mínimos de salud y limpieza para poder aprovechar mejor sus estudios. Se creó también la Inspección de Edificios Escolares con el propósito de que las instalaciones educativas tuvieran las condiciones adecuadas que requería la enseñanza moderna. Desde un punto de vista económico, el gasto destinado a la instrucción primaria fue creciendo, con algunas variantes, desde 1887, año en que el gobierno del estado se hizo cargo de las escuelas primarias municipales, como se observa en el siguiente cuadro:

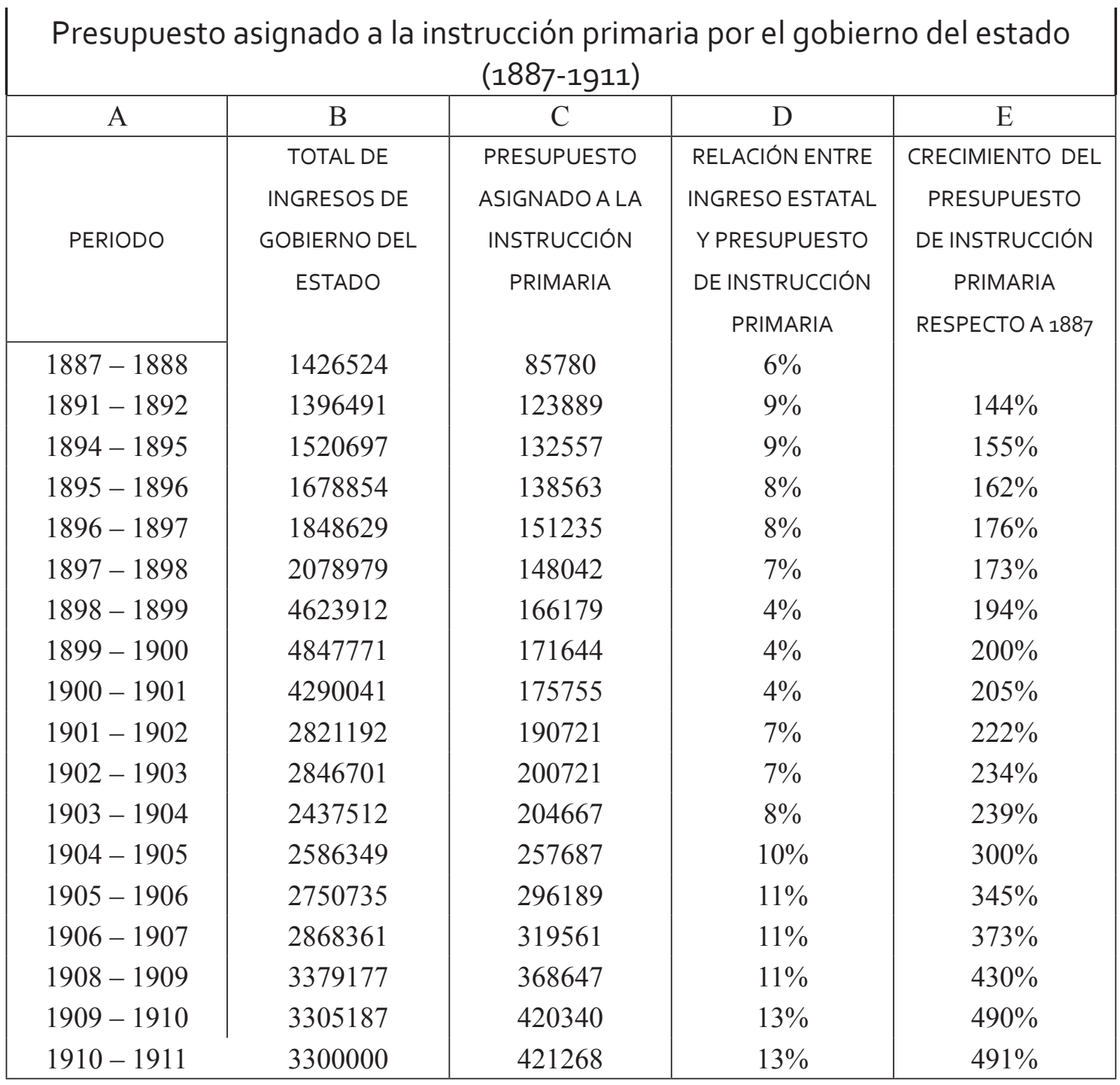

Fuente: elaborado con base en García, 1992. 
Si bien en términos porcentuales el presupuesto asignado a la instrucción primaria sufrió algunos altibajos entre 1895 y 1903 (véase columna D), en términos absolutos tuvo un crecimiento respecto al presupuesto de 1887 (véase columna E). Sin embargo, este sostenido incremento en el financiamiento de la educación primaria no repercutió de manera proporcional con el aumento de la asistencia a los establecimientos oficiales. Además, el crecimiento en la matrícula no implicaba necesariamente una mayor concurrencia escolar, ya que debido al carácter obligatorio de la enseñanza elemental muchos padres registraban a sus hijos en las escuelas pero éstos podían no presentarse a clases. Este comportamiento diferenciado entre matrícula y asistencia en las escuelas primarias oficiales de la ciudad se muestra en el siguiente gráfico:

\section{Conportamiento de la matricula, asistencia y aprobaciónen las escuelasprimarias oficiales de Guadalajara durante elperiodo $1894-1910$}

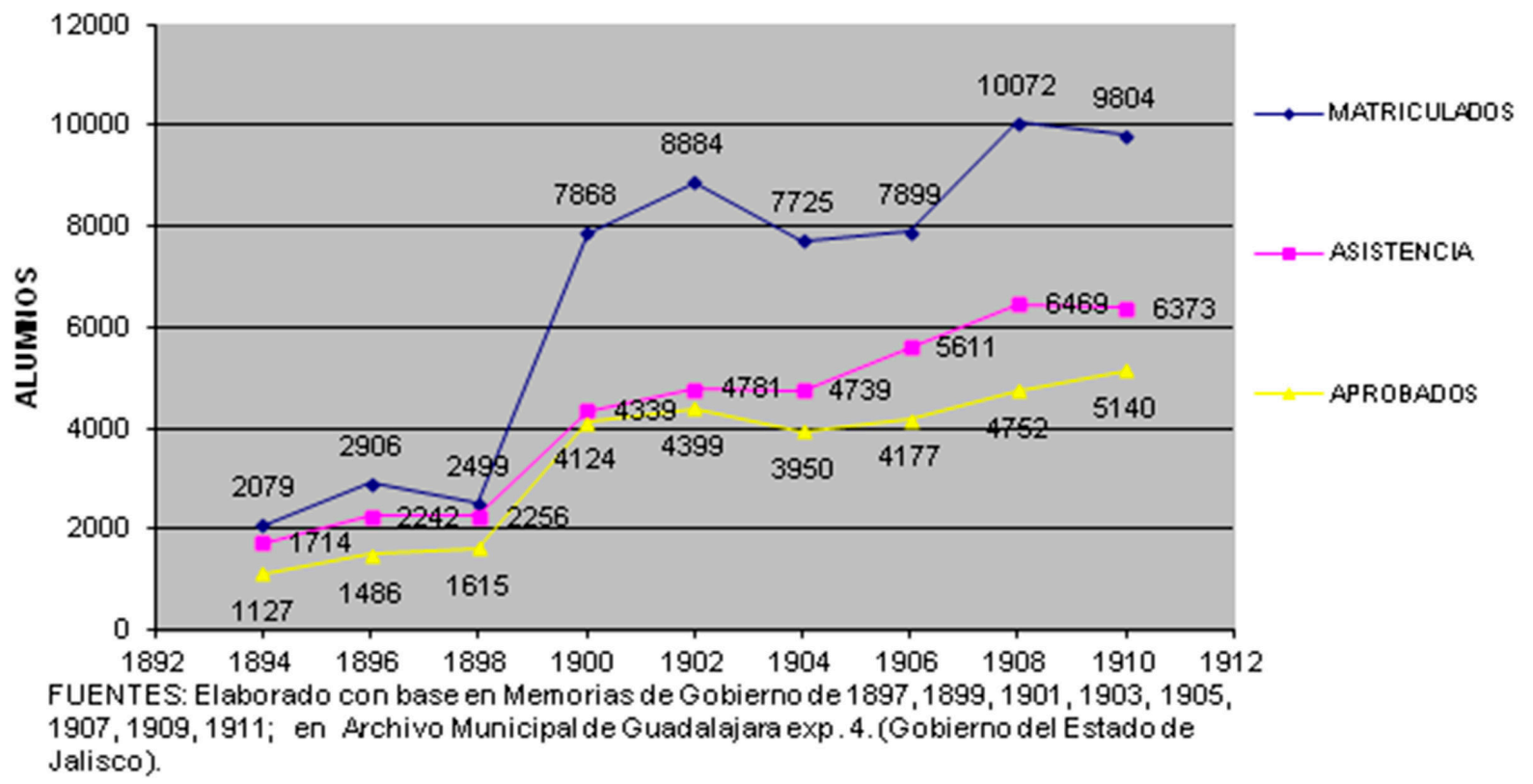

Sin embargo, la expansión de la oferta escolar no muestra las características de la enseñanza que se otorgaba en los planteles educativos, pues las escuelas no sólo han sido el marco en que ocurre la enseñanza, sino también un medio que constriñe y orienta la acción de los menores. Esto es, el mismo ambiente escolar ha impuesto a los niños cierto ordenamiento disciplinario, por medio del cual éstos interiorizan el sistema de valores del contexto en el que estudian.

En el caso de Jalisco, el gobierno del estado se esforzó en formar "discípulos", cuya raíz etimológica proviene del latín "discipulus" — sujeto que se somete a la disciplina— palabra que en 
Niñez y régimen disciplinario: una mirada sociocultural a la educación de antaño

sus orígenes se refería aceptar azotes de penitencia (Corominas \& Pascual, 1980). De esta manera educación y castigo convergían en el régimen disciplinario. La disciplina se convirtió en una condición para la enseñanza de los menores, por lo cual fue una preocupación de los diferentes sistemas escolares tapatíos durante el porfiriato.

El sistema de vigilancia fue considerado un dispositivo pedagógico para moldear la conducta de los niños. El Reglamento de Instrucción Pública del Estado de Jalisco de 1904 regulaba el comportamiento infantil hasta en los más mínimos detalles. La forma de sentarse, de pararse, de caminar, de hablar, de dirigirse a los otros estaba rigurosamente estipulada en este código de comportamiento. Allí se recomendaba al maestro colocarse en algún lugar estratégico para observar el actuar de los menores en todos sus detalles, pues se debían desarrollar las clases con el mayor silencio posible. Allí se prescribía el orden que se debía asumir durante las lecciones:

$72^{\circ}$. Para prevenir todo desorden durante las lecciones, el maestro procurará:

I. Que los discípulos estén sentados correctamente.

II. Que las manos estén sobre las mesas para evitar juegos y travesuras debajo de ellas.

III. Que los pies estén colocados paralelamente en el suelo.

IV. Que todos los discípulos tengan la mirada fija en los ojos del maestro, para evitar toda distracción, charla, risa, lectura clandestina, etcétera.

Lo prescrito en los incisos de este artículo será ejecutado por los alumnos a la voz de ¡Atención!, pronunciada por el maestro.

$73^{\circ}$. Llegada la hora de recreo, los alumnos, formados en perfecto orden saldrían al patio destinado para tal objeto. El profesor, a fin de evitar en lo posible los accidentes, vigilará el juego de los niños y los acostumbrará a que durante la recreación satisfagan sus necesidades.

$74^{\circ}$. Terminando el recreo, los niños se formarán y entrarán a sus clases con el mismo orden con que salieron. Antes de continuar con los trabajos del día, el profesor pasará lista de asistencia.

$75^{\circ}$. Al terminar las labores, en la mañana o en la tarde, los alumnos volverán a salir del salón de clase con el mismo orden.., y los profesores tendrán cuidado de que los niños no formen corrillos delante del establecimiento (Gobierno del Estado de Jalisco, 1904).

Cuando los niños no mantenían la debida compostura, correspondía al profesor recurrir a medidas de control como lo eran: la reprobación con el gesto y la mirada; la reprensión privada o pública; las notas desfavorables; la privación de recreos o paseos; la realización de trabajos extraescolares; la detención después de clases; la suspensión temporal o la expulsión definitiva del alumno insumiso. 


\section{La disciplina en la vida escolar cotidiana}

En este apartado damos cuenta de la manera en que era educada la niñez de Jalisco en los intersticios de los siglos XIX y XX. Para su construcción se utilizaron memorias y fuentes literarias, pues las consideramos un recurso imprescindible para recuperar el punto de vista de los cotidianos de los actores de la historia.

Si bien a principios del siglo veinte sólo la educación primaria era obligatoria, era común que previamente enviaran a los chiquillos a algunas improvisadas escuelitas en las propias casas de estrictas viejecillas quienes introducían a los menores en los rudimentos de la religión, las vocales y los números, pero sobre todo aprendían la disciplina escolar. Estas escuelitas recibían el mote de "amigas" pero no tenían nada de amigables, pues las instructoras solían recurrir a los medios tradicionales de control de la época para que los pequeños "entraran en cintura": reprimendas, suspensiones, actos de penitencia, palmetas y golpes, entre otros. El lema "la letra con sangre entra" muchas veces se tomaba "a pie puntillas". Salado Álvarez recordaba que fue víctima de estos procedimientos de enseñanza cuando a él y a otra parvulita, arrodillados y con los brazos en cruz, les tomaba el catecismo una furibunda educadora: "Nos atrajo a sí la buena señora, nos preguntó con voz agigantada si llevábamos aprendida la lección y luego nos apretó entre sus rodillas con tal violencia que nos hizo daño. Empezamos a llorar las dos víctimas, mientras ella nos tranquilizaba a su modo: Silénciense y les doy su gala" (Salado, 1985: 52).

El carácter disciplinario se aprendía desde los más tiernos años en los recintos escolares. José López Portillo y Rojas en su novela Los Precursores, describe cómo los pequeñines orientados por golpe de unas castañuelas marchaban por patio y corredores haciendo giros militares. Mientras marcaban el ritmo con sus pies iban cantando:

Marchando vamos amigos, Con el paso siempre igual; De desorden enemigos, Todos haremos al compás (1976: 71-72).

Ingresar al recinto escolar debía ser muy doloroso para la mayoría de los pequeños, sobre todo si no habían asistido a una "escuela de párvulos" en las inmediaciones de su casa. Llegar a un impersonal y frío edificio más o menos lejano y ajeno de la calidez del hogar; encontrarse entre el bullicio de más de cien rapazuelos; escuchar el grito abierto del director para mantener la autoridad sobre los atrabancados "mocosos"; acomodarse en las duras bancas de una lúgubre aula, al lado de un travieso y hasta belicoso compañerito; encontrarse en un mundo que reglamentaba formas de comportamiento hasta entonces desconocidas; recibir órdenes de una desconocida maestra y hasta ganarse la primera amonestación con sabor a regaño; todo ello debía figurar como un horrendo caos para quien hasta entonces había estado pegado a las faldas de su madre, de su nana o de sus tías. 


\title{
Niñez y régimen disciplinario: una mirada sociocultural a la educación de antaño
}

Después de que los pequeños se reponían de este sorprendente impacto inicial, se debían enfrentar al sistema de mandos, órdenes y reglas que constituían la organización escolar. Traer cara y manos limpias; la ropa más o menos arreglada; aprender a mantenerse quietos durante horas; atender las indicaciones de la profesora, eran algunos de los elementos de un aprendizaje que debía ser prontamente incorporado, si no se quería sufrir las funestas consecuencias de una mala asimilación: amonestaciones, regaños, burlas, pellizcos, palmazos, etc. Ante tales adversidades es posible que muchos infantes quisieran abandonar este martirio inicial y tal vez más de alguno de ellos actuara como lo hizo en un su mocedad el escritor Juan José Arreola en su natal Zapotlán:

\begin{abstract}
Me negué a regresar a la escuela. Y no hubo manera de llevarme. Me pegaban y me pegaban una y otra vez y yo nada, me rebelaba y pateaba y era inútil que volvieran a pegarme... Mi padre me agarró un día y me llevó arrastrando a la escuela, sí, materialmente arrastrando delante de toda la gente. Entre el maestro y mi padre me metieron a la fuerza a la escuela y cerraron las puertas con aldabas de cruz. En un intento por escapar me subí a la reja, pero el maestro me bajó a chicotazos. Me dejaron en el suelo llorando, y así fue durante varios días, hasta que yo mismo me di cuenta que así no podía llegar a ninguna parte (1994: 33).
\end{abstract}

En un régimen institucional orientado por el lema de "orden y progreso", la escuela procuraba reproducir en sus aulas dicha política. Así, Agustín Yánez recordaba que para salir de la escuela debía mantener el más completo silencio, para después formar rígidas filas y marchar militarmente rumbo a la calle, pero invariablemente este ritual sufría los tropiezos de los inquietos jovenzuelos:

Uno o dos ruidos. Ni tan uniformes. Rastreo de pies. Y en castigo, para que aprendan la disciplina:

-A sus lugares: uno, dos.

Quieras que no, otra vez el insufrible encajonamiento de pies sobre los pupitres. Y al cabo de un eterno minuto, con inalterable rigidez:

-A ver si ahora quieren salir. ¡De pie: uno, dos! Cubiertos. Señor López, ¡cubierto! Silencio ¿Ha oído usted, señor Hermosillo? ¿Hasta qué hora atiende usted?

Al fin, la orden de salida. Todavía en el patio:

-¡Firmes! Los señores que estén en la lista por no haber sabido la lección, un paso al frente... Los deudores, al salón de estudio. Los demás firmes: buenas tardes.

¡Buenas tardes!

-Flanco izquierdo: ¡izquierda! De frente: ¡avancen! Señor López, sepárese de la fila. Y es que el señor López -señor de once años- va metiendo zancadilla al compañero de adelante (1985: 63-64).

El orden y el silencio solían imperar en las escuelas de entonces, atendiendo un sistema pedagógico donde preponderaba el canturreo del maestro seguido por la repetición mecánica y memorización. Sin embargo, había algunos colegios en los que se emulaba la competencia entre estudiantes. Así 
la férrea disciplina del acuartelamiento cuasi-militar era sustituida por escuadrones en guerra académica. Trinidad González recordaba cómo en su prestigiado colegio su maestro dividía al grupo en dos bandos, en los que se interpelaban unos a otros con sagaces preguntas. Quien no contestara era considerado "muerto". De esta manera, "por eliminación perduraba la competencia hasta que quedaban los dos últimos, cada uno sacaba de la manga preguntas fulminantes, hasta que uno de ellos caía y quedaba sólo el líder que era aclamado por sus maestros, sus compañeros y el director" (2000: V).

Esta era no sólo una manera de aumentar la ilustración de los estudiantes, sino de inducirlos a la disciplina del estudio y de fomentar virtudes "viriles" como el pundonor, la tenacidad e incluso la humildad, como en los casos en que debían aceptar su derrota, e incluso festejar el triunfo del contrario. Quizá el mayor propósito de estos educadores consistía en hacer de cada muchachillo un ser civilizado y de finos modos, acorde con la prosapia de sus apellidos, pues, como señalaba Francisco Escalante, los maestros de entonces “...nos corregían cuando faltábamos a las buenas costumbres, tanto en la forma de hablar como en la manera en que nos conducíamos en nuestras relaciones hacia ellos, como con nuestros compañeros de escuela" (Escalante, 1994: 41).

Sin embargo, en la escuela pública sería más frecuente que a los alumnos los educaran a través del canturreo repetitivo, la escritura de interminables planas y a la realización de complejas cuentas, además de las aburridas explicaciones de sus maestros. Sin embargo, era muy factible que los alumnos buscaran estrategias tanto para librarse de las lecciones como para "ganarse al maestro", pues el estudio no era la única manera de obtener buenas calificaciones: "lambisconear" al profesor haciéndole mandados y cumpliéndole favores; poner cara de "mosquita muerta" después de haber cometido una fechoría; mantener correcta compostura cuando el maestro volteaba; y poder ser elegido para mantener el orden y hasta para nombrar la lista; pero quizá el medio más recurrente era "pedir licencia" para "hacer de las aguas". Ya afuera del salón se podría mordisquear la charamusca, hojear el libro de cuentos, y los mayores y arriesgados, fumar un cigarro y comer un dulce para despistar el fuerte olor a tabaco. Sin embargo, los menores debían cuidarse de que no los "agarraran con las manos en la masa", porque algunos profesores eran expertos en aplicar los castigos más diversos y severos, como lo recordara Agustín Yáñez:

Es una fiera la señorita, endemoniada para eso de inventar castigos: en la pared, con las piernas medio dobladas; en mitad del patio; hincado al sol; o jalar los cabellos con el dedo muy repegado en la cabeza y subiéndolo poco a poco, recio; o varetazos en las corvas o en los brazos, con una varita de membrillo muy delgada y muy flexible; o reglazos en las palmas de las manos, que se hinchan y se amoratan (1958: 93).

José R. Benítez nos ofrece una descripción muy puntual del sistema de castigos que solían usar los profesores para disciplinar a los menores. La hora de mayor temor para los chiquillos era el momento en que el viejo docente "tomaba la lección". El educador iba pasando por las mesas de 
los estudiantes preguntado, si el chiquillo equivocaba un poco la contestación solía recibir un coscorrón corrector, pero cuando el menor no atinaba la respuesta entonces don Atilano solía utilizar la hincada y el cepo para corregir a los más lerdos: "El primero consistía en arrodillar al estudiante con los brazos en cruz, por más o menos tiempo, según el castigo impuesto; el segundo, más cruel todavía, el alumno estaba obligado a inclinar su cuerpo hasta colocar la cabeza debajo de la mesa de don Atilano, por el tiempo que éste juzgaba conveniente" (2003: 81). Pero, a lo que más temían los niños era la famosa regla que el anciano profesor usaba para controlar a los alumnos más traviesos e insumisos, entonces no había súplica que los librara de tamaña tunda:

...el castigado subía a la plataforma; el director descolgaba una regla larga y delgada que siempre estaba en vera; tomaba al chamaco por el cuello, tranquilamente untaba el fondillo del pantalón sobre las nalgas para evitar toda precaución protectora y ¡zaz! La regla zigzagueaba por el aire y caía de filito en las asentaderas del infeliz ajusticiado (Benítez, 2003: 81).

Este clima escolar represor sólo era expresión de una cultura violenta que también reproducían los estudiantes. Benítez observaba que debido a que los grupos eran muy grandes, el docente dividía el salón en grupos de diez alumnos, los cuales quedaban a cargo de un alumno más versado sobre el tema en cuestión, llamado decurión, con quien a coro repasaban las lecciones. Sin embargo, cuando el profesor salía del salón eran los propios decuriones quienes organizaban las "trompadas". Esto sucedía cuando...

principiaba el "aguacero", es decir, un ostentoso estudio a gritos, que tenía por objeto evitar que don Trini se diera cuenta de los mojicones que nos dábamos por parejitas, contando como era natural con la aquiescencia y disimulo de los decuriones quienes.., en calidad de jueces, pronunciaban su fallo, en casos dudosos de victoria. Ese fallo, no obstante, concedía a los contendientes derrotados el derecho de "dos agarrones" más, después de los cuales se pronunciaba el definitivo e irrevocable (Benítez, 2003: 155).

Para algunos niños los golpes no era la peor pena que podían sufrir. Al parecer en cada escuela existía un salón de castigos denominado "el calabozo". Este era utilizado como un recurso para asustar a los niños que no querían cumplir con sus deberes y para tratar de corregir a los más aguerridos. Por ejemplo, el pintor Ixca Farias recordaba como un maestro ante cualquier falta descubierta a un alumno enviaba al infractor al gabinete: el cuarto oscuro que fungía como calabozo. Así, cuando cierto alumno alguna vez protestó por el castigo impuesto "le aumentó la pena a quince horas diarias, y como seguía protestando le aumento el castigo a treinta horas diarias de gabinete" (1963: 23-24). 
No era de extrañar que en ese ambiente marcial, algunos de los menores más sagaces y atrevidos se hartaran de tantas reglas y castigos, y de vez en cuando optaran por "hacer venado". Asiduamente dos o tres de los compañeros más íntimos y bullangueros se encaminaban rumbo al río, a un baño público o al descampado donde disfrutaban de una horas de libertad, sin profesores, ni libros y ni reglas tediosas. El escritor Manuel Aguirre, nos legó una estampa de uno de esos días de "pinta":

Cuando en vez de la escuela, Se iban haciendo La Pinta, Escribiendo y dibujando

Sin usar papel ni tinta;

Despreciando la enseñanza

Que los llevara a la ciencia;

Prefiriendo la ignorancia

De sus actos de inconsciencia. (...)

Sin perjuicio que el maestro

Les doblara la ración

Obligándolos que hicieran

Un acto de contrición

A pesar de los pesares

$\mathrm{Y}$ de aquellas algaradas

No faltaba quien volviera

Otra vez a sus andadas

(Aguirre M. , 1958: 224-225).

Para fortuna de estos menores, tanto en las escuelas oficiales como católicas se guardaban los días santos. Lo que significaba que los escolares tendrían una semana de vacaciones que no siempre utilizaban en los actos piadosos, ni penitentes, sino para realizar actividades más placenteras y carnales, cómo lo narrara Agustín Yáñez, en boca de un alumno de primaria:

Desde mañana empezarán las vacaciones de Semana Santa. ¡Cuán a gusto! El cuerpo y el alma se estiran de gozo. Poder levantarse tempranito a armar con los muchachos vecinos un desfile en que suenen botes y cornetas; salir al campo, cuando aún está a oscuras, e ir a pie hasta Zapopan o hasta el Batán y la Experiencia; no tener latas de puntualidad y del aseo, no ver a los maestros ni a los compañeros que nos repugnan. Por ocho o diez días, hacernos la ilusión de ya ser hombres independientes, sin obligaciones, compadeciendo desde muy alto las miserias de la vida de escuela, las ridiculeces de los profesores a quienes ya nunca hablaremos; también hacernos la ilusión de que ya jamás iremos en fila, formados como soldados, y hablaremos cuando nos dé la real gana, y toda la gente será igual a nosotros, y poco nos importará que los mapas y las plantas y los resúmenes se manchen, y que los sólidos salgan chuecos... Leer novelas en lugar de geografías y matemáticas (1985: 73). 
Niñez y régimen disciplinario: una mirada sociocultural a la educación de antaño

\section{Reflexiones finales}

En la perspectiva oficial se consideraba que la niñez constituía una etapa en la evolución del individuo. La tarea del educador consistía en ejercitar las emergentes facultades físicas, morales e intelectuales de los menores a fin de estimular su desarrollo. Esta normatividad estaba sustentada en una visión positivista/evolucionista de la educación y de la sociedad. Según esta posición, el mundo, al igual que el niño, se encontraba en un constante cambio. Es decir, las sociedades se iban desenvolviendo por etapas, de las más primitivas hasta las más civilizadas. México podía entrar en esa etapa más progresista a condición de hacer de cada niño un ciudadano ilustrado, laborioso y respetuoso del orden instituido. Así, el amor a la patria, al progreso y a las instituciones eran los valores que más se inculcaban a los niños en las escuelas oficiales.

La rígida normatividad de las escuelas obedecía a que predominó la visión de un niño proclive al mal, al que se deberían reprimir sus inclinaciones naturales a fin de corregir su conducta. Esta representación se complementaba con la idea de que el mundo era una prueba que todo infante debía padecer a fin de poder vivir armónicamente en sociedad. Al niño se le debía formar para ser un modelo de virtud para sus familiares y conciudadanos. Para ello debía adquirir valores como la obediencia y la sumisión al orden establecido.

Sin embargo, aunque los diferentes regímenes educativos coincidían en que en la escuela el niño aprendía a ajustar su conducta al orden institucional, en la práctica los comportamientos infantiles podían ser muy diferentes, pues con frecuencia los menores interrumpían la monotonía escolar con sus espontáneas ocurrencias y su irredenta indisciplina. Cuchichear y jugar a espaldas del maestro; divagarse de la clase entre las fantasías de su rica imaginación; dirimir diferencias por medio de retos, discusiones y hasta puñetazos; crear sus propias reglas del juego y convivencia, eran algunas de las múltiples formas en que los niños resistían la rigidez escolar. En fin, los menores de antaño — como los de hoy_construían su propio mundo en los márgenes de la normatividad institucional.

\section{Referencias}

Abreu, E. (1954). Del alba sería. México: Ediciones Botas.

Aguirre, M. (1958). Teocaltiche en mi recuerdo. México: Costa-Amic, Editor.

Aguirre, M. E. (2002). Una invención del siglo XIX: la escuela primaria. (1780-1890). En L. E. Galván, Diccionario de historia de la educación en México. (Disco compacto) (pág. s/p). México: CIESAS; CONACYT; UNAM.

Ahumada, M. (1904). Reglamento de la Instrucción Pública. Colección de los decretos, circulares y órdenes de los poderes del Estado de Jalisco, XXI. Guadalajara, Jalisco, México: Tipografia de J. Cabrera.

Alcubierre, B. (2003). En busca del niño lector: representaciones de la lectura infantil en la primera mitad del siglo XX mexicano . En SOMEHIDE, Memoria del VI Congreso Iberoamercano 


\section{Oscar Reyes Ruvalcaba, Celia Luévanos Aguirre y Eurídice Minerva Ochoa Villanueva}

de la Historia de la Educación Latinoamericana (pág. s/p). San Luís Potosi: SOMEHIDE; CESU-UNAM; Colegio de San Luís.

Alcubierre, B., \& Carreño, T. (1996). Los niño villistas. Una mirada a la historia de la infancia en México, 1900-1920. México: Instituto Nacional de Estudios Históricos de la Revolución Mexicana.

Arreola , J. J. (1994). Memoria y olvido. Vida de Juan José Arreola. México: Consejo Nacional para la Cultura y las Artes.

Arreola, J. J. (1994). Memoria y olvido. Vida de Juan José Arreola. México: Consejo Nacional de la Cultura y las Artes.

Benítez, J. (2003). De la Vida que dejé atrás... Apuntes que a nadir importan. Guadalajara: Emprendedora Universitaria.

Beteta, M. R. (1966). Jarano. México: Fondo de Cultura Económica.

Castillo, A. (octubre-diciembre de 1998). Entre la criminalidad y el orden cívico: imágenes y representaciones de la niñez durante el porfiriato. Historia Mexicana, XLVLIII(2), 380-392.

Corominas, J., \& Pascual, J. (1980). Diccionario crítico etimológico castellano e hispánico. Volumen II. Madrid: Gredos.

De la Cabada, J. (1984). María La Voz. México: Fondo de Cultura Económica.

Escalante, F. (1994). Analco, ayer, hoy y siempre. Guadalajara: Editorial Conexión Gráfica, S.A. de C.V.

Farías, I. (1963). Casos y cosas de mis tiempos. Guadalajara: Impresa por el doctor Pedro Rodríguez Lomelí.

Fernández de Lizardi, J. J. (2001). El Periquillo Sarrniento. $26^{a}$. edición. México: Porrúa, S.A.

Foucault, M. (1970). Arquelogía del saber. México: Siglo XXI editores.

Foucault, M. (1983). Vigilar y castigar el nacimiento de la prisión (8va. ed.). México: Siglo XXI editores.

Galván, L. E. (2003). Un periódico para la niñez desvalida decimonónica. En COMIE, Memoria del VII Congreso Nacional de Investigación Educativa (pág. s/p). Guadalajara: Consejo Mexicano de Investigación Educativa.

García, G. (1992). Poder, educación y región: municipio, gobierno del estado, arzobispado y escuelas primarias en Guadalajara (1867-1914). México: Instituto Mora.

Gobierno del Estado de Jalisco. (1897, 1899, 1901, 1903, 1907, 1909, 1911). Memorias de Gobierno. Guadalajara: Archivo Municpal de Guadalajara, expediente 4.

Gobierno del Estado de Jalisco. (1904). Reglamento de la Instrucción Pública. En A. G. Jalisco, Colección de los decretos, circulares y órdenes de los poderes del Estado de Jalisco, Tomo XXI. Guadalajara: Tipografia de J. Cabrera.

González Navarro, M. (1994). Sociedad y cultura en el Porfiriato. México: Consejo Nacional para la Cultura y las Artes. 
Niñez y régimen disciplinario: una mirada sociocultural a la educación de antaño

González, T. (2000). La plazuela de la aduana. Añoranzas. Guadalajara: Ediciones Pacífico, S.A. Jiménez, G. (1997). "Niños de la Independencia, dirigentes de la nación, 1800-1890”. En Jáuregui, Luis y Serrano, José Antonio coord. Historia y Nación. II. Política y diplomacia en el siglo XIX mexicano. Mexico: Colegio de México.

Lafaye, J. (2002). Quetzalcóatl y Guadalupe: La Formación de la Conciencia Nacional en México. México: Fondo de Cultura Económica.

Larroyo, F. (1947). Historia comparada de la educación en México. México: Editorial Porrúa, S.A. López Portillo , J. (1976). Los precursores. Tomo I. Guadalajara: Ayuntamiento de Guadalajara. Magdaleno, M. (1954). El ardiente verano. México: Fondo de Cultura Económica.

Meneses, E. (1983). Tendencias educativas oficiales en México: 1821-1911. La problemática de la educación mexicana en el siglo XIX y principios del siglo XX. México: Editorial Porrúa, S.A.

Prieto, G. (1996). Memorias de mis tiempos. 6a. edición. . Editorial : Porrúa, S. A.

Romero, E. (1939). Datos biográficos del señor doctor Máximo Silva. México: Tipografía HispanoMexicana.

Silva, M. (1917). Higiene Popular: colección de conocimientos y de consejos indispensables para evitar enfermedades y prolongar la vida arreglado para uso de las familias. México: Departamento de Talleres Gráficos de Fomento. México: Departamento de Talleres Gráficos de Fomento.

Spencer, H. (1889). La educación intelectual, moral y física. Nueva York: D. Appleton y compañia. Valle-Arizpe, A. (1990). Canillitas. México: Consejo Nacional para la Cultura y las Artes/Colección Letras Mexicanas 3.

Yáñez, A. (1958). Flor de juegos antiguos . Guadalajara: Ediciones del Banco Industrial de Jalisco. Yáñez, A. (1985). Los sentidos del aire. México: Fondo de Cultura Económica.

Recibido: 30/06/14

Dictaminado: 25/11/14

Corregido: 09/03/15

Aceptado: 19/03/15 
Oscar Reyes Ruvalcaba, Celia Luévanos Aguirre y Eurídice Minerva Ochoa Villanueva 